\title{
38. Manufacturing and characterization of CNT based polymer composites
}

\author{
G. Satish ${ }^{1}$, V. V.S. Prasad ${ }^{2}$, Koona Ramji ${ }^{3}$ \\ ${ }^{1,2}$ Department of Marine Engineering, Andhra University, Visakhapatnam, 530003, India \\ ${ }^{3}$ Department of Mechanical Engineering, Andhra University, Visakhapatnam, 530003, India \\ ${ }^{2}$ Corresponding author \\ E-mail: ${ }^{1}$ geerisatish@gmail.com, ${ }^{2}$ prasadau@gmail.com, ${ }^{3}$ ramjime@yahoo.co.in
}

Received 1 August 2017; received in revised form 4 September 2017; accepted 14 September 2017 DOI https://doi.org/10.21595/mme.2017.19121

Check for updates

\begin{abstract}
Carbon nanotubes have been the concentration of all-encompassing research due to the excellent mechanical, thermal, electrical and magnetic properties. In the present work fifteen specimens of polymer composites is manufactured, multi walled carbon nanotubes (MWCNT's) are considered as filler material for proposed volume based amount and for three unique direction of E glass fiber. The effect of different percent loadings of MWCNTs on the morphology and thermal behavior of the composites had been inspected. Thermal analysis investigation showed that a clear improvement of thermal stability of composites increased with increasing MWCNTs content. The experimental results are compared with statistical results and found to be in good agreement.
\end{abstract}

Keywords: multi walled carbon nanotubes, carbon nanotubes, glass mat, thermal behavior.

\section{Introduction}

Sumio Ijima developed carbon nanotubes (CNTs) in 1991 [1]. The researchers concentrated on this material for the reason that they have unique structural, mechanical, electrical, thermal and other materials related properties of carbon nanotubes [2-4]. It gives amazing opportunities for the development of new material. Carbon nanotubes is the key basic of the nano technology, as it controls the issue on nanoscale and its consequences for properties of composite materials. CNT's have been utilized as a part of numerous potential applications such as nano electronic and photovoltaic devices [5,6], super conductor [7], electromagnetic actuator [8], and nano composite materials $[9,10]$. A polymer composite comprises of a polymer matrix with nano-sized filler. A wide range of sorts of filler have been tried and are additionally utilized monetarily to enhance the properties of polymers. In this unique situation, CNTs is a standout amongst the most fascinating filler for future applications.

Due to their uncommon properties and large aspect ratio, minute bulk of CNTs can have a large influence on the properties of a composite [11-13]. The carbon nanotubes are insoluble in any organic solvent and troublesome in dispersion in a polymer matrix due to strong Vander Waals interaction. Additionally, carbon nanotubes tend to form into aggregates and it is a negative impact on the properties of composite. In general, there are several methods for dispersion of $\mathrm{CNT} /$ polymer composites.

They can be summarized as magnetic stirring, shear mixing, reflux, most commonly used ultra sonication [12], solution mixing, melt blending, In situ polymerization, latex technology and layer-by-layer deposition [14]. Solution mixing is one of common method for the fabrication of CNT/polymer laminated composites because it can be accepted for small sample size [15-17]. Blending of solution involves in three methods; dispersion of CNT's in a solvent by mechanical mixing, magnetic agitations or sonication. Carbon nanotubes can also dissolve in polymer resins at room or elevated temperature [14]. Melt blending is commonly used method to fabricate CNT/polymer nano composites. Thermo plastic polymers, such as polypropylene [18], polystyrene [19], poly (ethylene 2, 6-naphthalate) [20] can be processed as matrix materials in this method [14]. In situ polymerization is an efficient method for uniform dispersion of CNT's in a thermo setting polymers. The advantage of this method is that covalent bonding can be formed 
between functionalized CNT's and polymer matrix, hence much improved mechanical properties of composite through strong interfacial bonds [14, 30].

The fabrication of CNT based polymer nanocomposites most part done through resin transfer moulding and hand lay-up method. Hand lay-up method is a reliable process; it is by its nature very slow and labor-intensive. Resin transfer moulding is another method used for complex shapes at relatively at high production rates $[24,25]$. It should be noted that nano composite materials are significant in the emerging field, many studies are being made to devise new processing methods that can produce nano composites with unique structure and properties for required and for the defined applications [21-23].

Hsu et al. [26] investigated thermal stability of MWCNT/biphenyl liquid crystalline epoxy composites by TGA. The decomposition temperature (Td) demonstrates a continuous increment up to $2.0 \mathrm{wt} \%$ epoxy functionlized-CNT (e f-CNT) composition in epoxy matrix. This might be ascribed to the huge increment of interfacial bonding between the matrix and the reinforcement. Bhattacharya et al. [27] examined on multi wall carbon nanotubes based nanocomposites. The thermal stability of the RAMs namely RAM-MW, RAM-Ti, RAM-Ti@MW and RAMTi@MW/Fe were analyzed by TGA instrument, in nitrogenous atmosphere. RAMTi@MW/Fe is comparatively most thermally stable material among all. Maximum weight loss for RAM-MW, RAM-Ti, RAM-Ti@MW and RAMTi@MW/Fe in 81, 79, 77 and 74 \% respectively, decreasing trend which may be due to the increase in multiple bonding sites provided by different fillers presented in the composites.

In the present study, for three different orientations and for the proposed percentages of carbon nanotubes composites are fabricated. By using magnetic stirrer, the proposed percentages of CNT are mixed and are followed by hand layup technique. The thermal behavior of the composites is investigated.

\section{Experimental details}

\subsection{Materials}

The fiber chosen were woven roving glass mat for fabricating specimens. Polyester, epoxy, phenolic and vinyl ester are mostly used as thermoset resins, the matrix materials used is LY556 (Bisphenol-A-Diglycidyl-Ether) epoxy resin and hardener is HY951 (Tri-ethylene-Tetramine). Multi walled carbon nanotubes are selected as the filler material for the high tensile modulus and strength, low aspect ratio, low density, high flexibility, excellent thermal and electrical properties. These are allotropes of carbon, made out of at least two concentric round and hollow shells of graphene sheets with diameter in the nano meter scale.

\subsection{Preparation of composite specimen}

Solution technique is used for fabrication of the CNT composites. The calculated amount of epoxy (LY 556) resin is taken into a glass beaker and four different volume percentages such as $1 \%, 3 \%, 5 \%$ and $7 \%$ of CNT are added with epoxy resin. Six layered of E glass fibers were used to fabricate. The fibers were directed at $\left[0^{\circ} / 90^{\circ}\right],\left[0^{\circ} / 45^{\circ}\right]$ and $\left[0^{\circ} / 135^{\circ}\right]$ orientation. A magnetic stirrer is used for homogeneous dispersion of multi walled carbon nanotubes in epoxy resin for proposed quantity of volume percentage, stirrer at different RPM for 30 minutes at room temperature. After well dispersion of CNT, HY951 hardener is carefully mixed with the epoxy/CNT solution in the ratio of 1:10 for curing of the composite. A rectangular mould of size $(300 \times 300 \times 3) \mathrm{mm}^{3}$ is used for making the CNT composite. For fabricating composites the mould is coated with one layer film of liquid polyvinyl alcohol as an easy releasing agent. A fifteen number of specimens were prepared with CNT based composites by hand lay-up technique. The fabricated specimens are shown in Fig. 1-3. Entrapped air and volatiles are removed by rolling the composite laminate with a smooth steel roller, which also ensured that the resin is uniformly 
distributed over the glass fiber surface. The process is repeated to get the composite laminate thickness of $3 \mathrm{~mm}$ plate. Finally, the composite has been allowed to fully cure at room temperature for 24 hours.

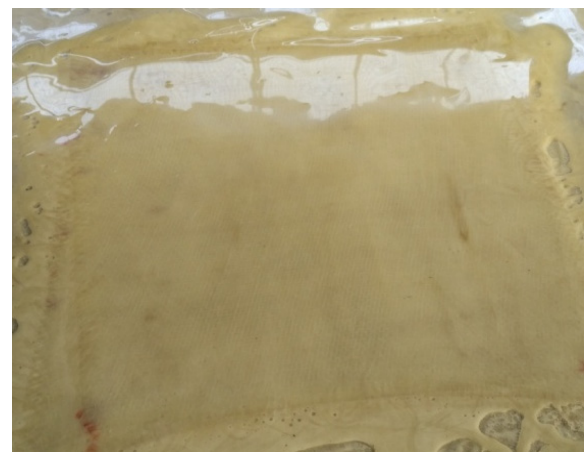

Fig. 1. Specimen containing $0 \%$ MWNT's for $\left[0^{\circ} / 90^{\circ}\right]$ orientation

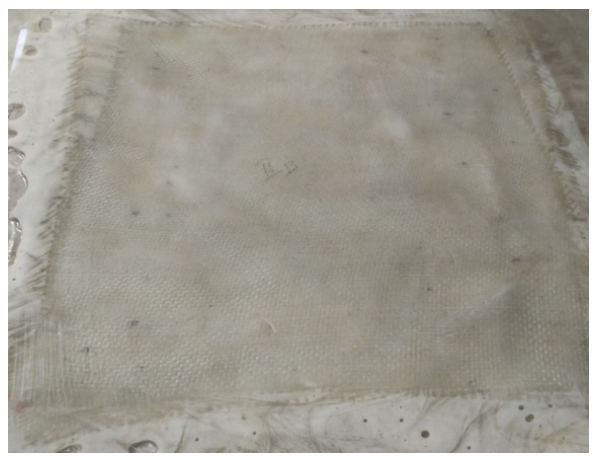

Fig. 2. Specimen containing $1 \%$ MWNT's for $\left[0^{\circ} / 90^{\circ}\right]$ orientation

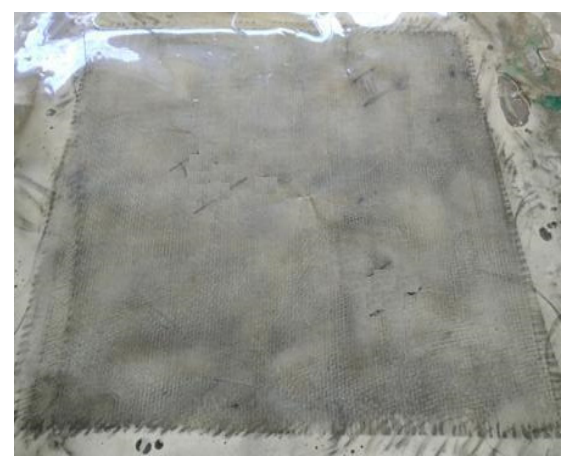

Fig. 3. Specimen containing $7 \%$ MWNT's for $\left[0^{\circ} / 90^{\circ}\right]$ orientation

\subsection{Thermogravimetric analysis}

Thermal degradation properties of the nanocomposites were measured by thermogravimetric analysis (TGA) from room temperature to $850{ }^{\circ} \mathrm{C}$ with a heating rate of $10{ }^{\circ} \mathrm{C} / \mathrm{min}$ under $N_{2}$ atmosphere. The measurements were conducted using 6-10 mg samples for fifteen composites. Weight retention/temperature curves were recorded.

\subsection{Statistical procedure}

A non linear regression analysis was done to build up a relationship for thermal degradation, weight loss and thermal decomposition with respect to the experimental data of specimens. In order to calculate error and to compare between the experimental data and the regression based data for each individual specimen graphs are plotted. Examination was performed utilizing Mini Tab software.

\section{Results and discussions}

\subsection{Morphological properties}

Scanning electron microscopy is utilized to investigate the dispersion of carbon nanotubes and surface morphology of the composite. The voids and pores may prompt to stress concentration and leads to premature failure of the composite during loading. As the cracks got started, the 
matrix materials were lost, generally the form of resin particles. The SEM evidence in Fig. 4 and 5 supports this explanation.

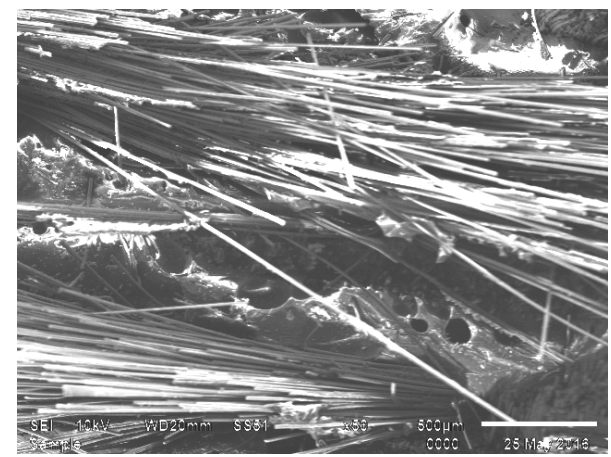

Fig. 4. SEM image showing matrix cracking and voids effect

Therefore, investigations of the surface topography on composite provide information on the interfacial adhesion that exists between the fiber and matrix material when reinforcing agent is incorporated. Homogeneous distribution of reinforcing agent MWNT's prompts to improvement of strength and toughness due to strong interaction between MWNT's and matrix materials. When reinforcing agent percentage increase beyond $5 \%$, the uniform dispersion will not take place and some aggregates appear, which prompts to lessen the properties of the composites. Agglomeration prompts to weaking of bonding of the fiber and the matrix material. Hence by loading on the composite, stresses drives the composite to failure in Fig. 6. Fig. 7 demonstrates the crack created in specimen, when placed in tensile experiment.

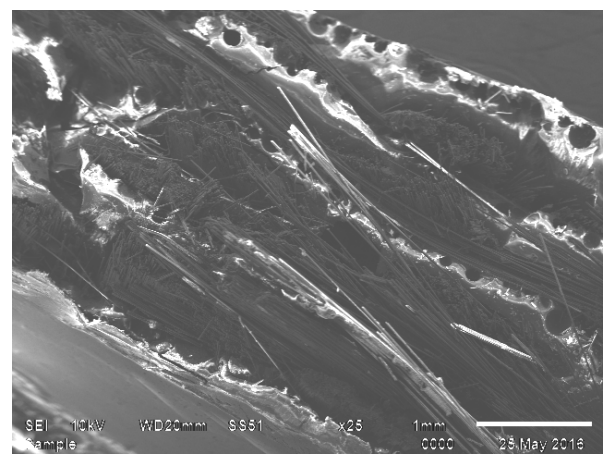

Fig. 5. SEM image showing fracture running along fiber-matrix material and flexural tested specimen

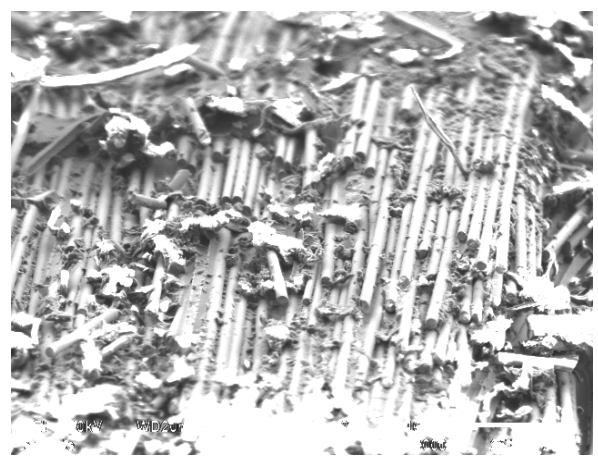

Fig. 6. SEM image showing agglomeration for $7 \%$ MWNT's for $\left[0^{\circ} / 90^{\circ}\right]$ specimen

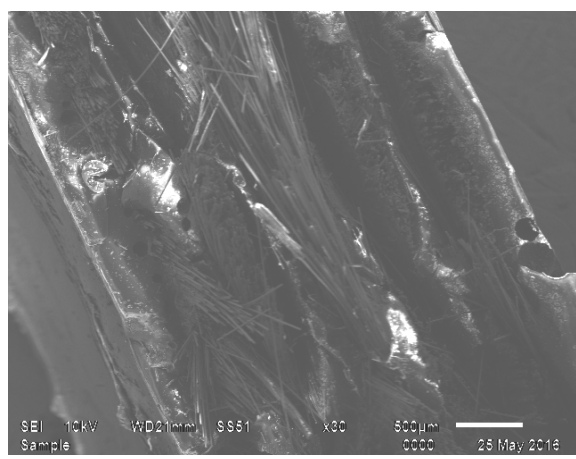

Fig. 7. SEM image of the fracture surface of the tensile tested specimen for $\left[0^{\circ} / 90^{\circ}\right]$ specimen 


\subsection{Thermal analysis of CNT based composites}

There are three primary mass loss processes. In the first stage, the slight mass loss below $100{ }^{\circ} \mathrm{C}$ could be attributed to the evaporation of absorbed water and $100^{\circ}-300^{\circ} \mathrm{C}$ the weight loss due to the removal of oxygen containing groups on the surface. In second stage, the temperatures from $300^{\circ}-500^{\circ} \mathrm{C}$ can be assigned to the oxidation process. In the last stage, the temperature from $500^{\circ}-800^{\circ} \mathrm{C}$ weight loss due to decomposition of carbon nanotubes as shown in Fig. 11, 12, 13 for $\left[0^{\circ} / 90^{\circ}\right],\left[0^{\circ} / 45^{\circ}\right]$ and $\left[0^{\circ} / 135^{\circ}\right]$ oriented composites respectively.

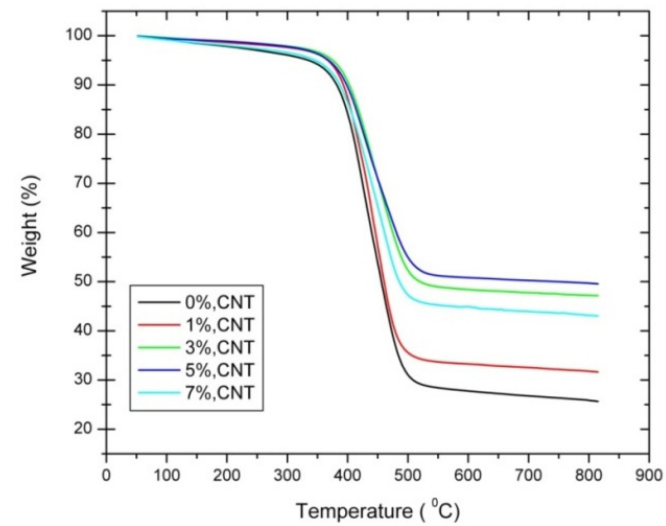

Fig. 11. TGA curves of different CNT percentages of $\left[0^{\circ} / 90^{\circ}\right]$ oriented nanocomposites

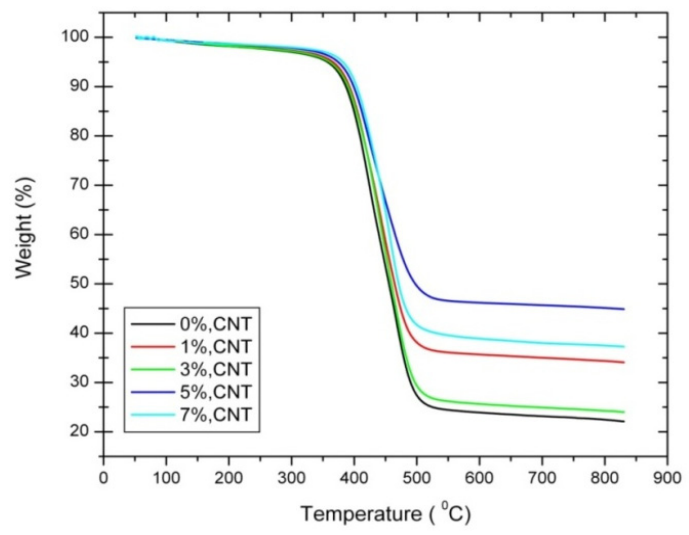

Fig. 12. TGA curves of different CNT percentages of $\left[0^{\circ} / 45^{\circ}\right]$ oriented nanocomposites

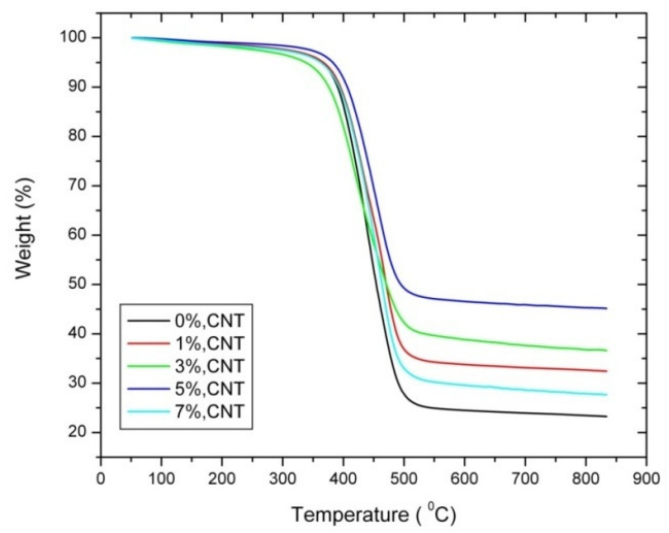

Fig. 13. TGA curves of different CNT percentages of $\left[0^{\circ} / 135^{\circ}\right]$ oriented nanocomposites

In the present study for $\left[0^{\circ} / 90^{\circ}\right],\left[0^{\circ} / 45^{\circ}\right]$ and $\left[0^{\circ} / 135^{\circ}\right]$ oriented composites, the carbon nanotubes based composite at $5 \%$ MWCNT is thermally stable up to $337.6{ }^{\circ} \mathrm{C}, 360{ }^{\circ} \mathrm{C}, 350{ }^{\circ} \mathrm{C}$ respectively and it was the highest among remaining percentages. The carbon nanotubes based composite at $5 \%$ exhibits better outcome in increasing the thermal stability of specimens. The results indicate that adding carbon nanotubes will raise the temperature of maximum thermal degradation. The reason for this higher thermal stability of composites may be due to increase in the degree of cross-linkage as well as in the crystallinity of matrix material.

The dependence of the decomposition temperature on MWCNTs content. As CNT content is increasing, the thermal decomposition temperature is also increased and later decrease for higher loading of CNT percentage, probably due to the ease of compact char formation for the composites during thermal degradation. The material will not starts decompose until that particular temperature. The composite with $5 \%$ MWCNT is comparatively most thermal stable material 
among all and does not decompose until $566^{\circ} \mathrm{C}, 552{ }^{\circ} \mathrm{C}, 554.5^{\circ} \mathrm{C}$ for different orientations. On the other hand, high concentration MWCNTs would definitely prevent its fine dispersion and more aggregation or bundles could often be formed because of Vander Waals force among the MWCNTs, thus deterioration the thermal stability of the composites.

The weight loss is less at $5 \%$ CNT concentration for $\left[0^{\circ} / 90^{\circ}\right],\left[0^{\circ} / 45^{\circ}\right]$ and $\left[0^{\circ} / 135^{\circ}\right]$ oriented composites. As CNT concentration is increased the weight loss is reduced up to $5 \% \mathrm{CNT}$ concentration, beyond that it increased as shown in Figs. 14, 15 and 16.

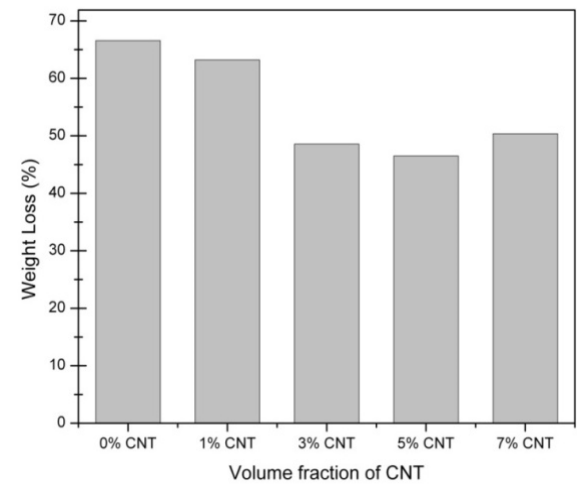

Fig. 14. Weight loss of different CNT percentages of $\left[0^{\circ} / 90^{\circ}\right]$ oriented nanocomposites

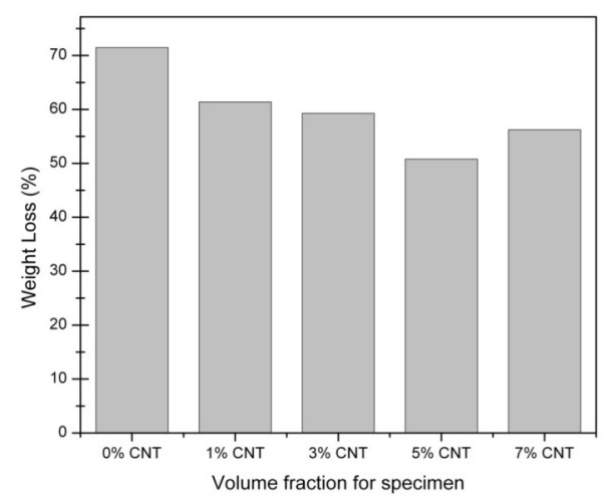

Fig. 15. Weight loss of different CNT percentages of $\left[0^{\circ} / 45^{\circ}\right]$ oriented nanocomposites

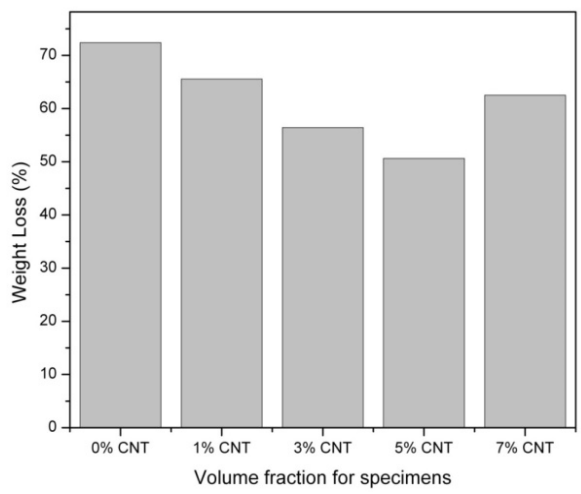

Fig. 16. Weight loss of different CNT percentages of $\left[0^{\circ} / 135^{\circ}\right]$ oriented nanocomposites

\subsection{Development of regression model}

In statistics, regression analysis is the technique for the modeling and finding analysis of numerical data consisting of values of dependent variables (response variables) and one or more independent variables(predictors). Several prediction techniques have been used to model the thermal properties of composite materials based on different parameters. Regression model is most helpful technique in determining the thermal properties of fiber-reinforced polymer composite. A positive effect is achieved, so we are considering thermal properties data for statistical prediction using regression model. The experimental data was used to generate a mathematical model using regression analysis. By using that equation, an error can be found by placing the experimental values in that equation. By comparing the experimental values and regression values an error can be found for thermal behaviour of the composites

Regression equation is formulated to get the relation between response/dependent variables i.e., thermal properties $(Y)$ and the input parameters i.e., volume percentage $(X)$. 


\subsubsection{Thermogaravometric analysis}

This function fits a polynomial regression model to the powers of a single predictor by the method. Interpolation and calculation under the curve are also given. The thermal properties are analysed by using thermogaravometric analysis have been formulated in polynomial equation by regression models.

For $\left[0^{\circ} / 90^{\circ}\right]$ oriented specimen:

$$
\begin{aligned}
& y_{\text {deg }}=-0.392 x^{2} 4.081 x+326.0 \\
& y_{\text {decom }}=-1.434 x^{2}+11.75 x+540.9
\end{aligned}
$$

For $\left[0^{\circ} / 45^{\circ}\right]$ oriented specimen:

$$
\begin{aligned}
& y_{\text {deg }}=-1.647 x^{2}+16.81 x+312.7 \\
& y_{\text {decom }}=-1.546 x^{2}+12.53 x+527.2
\end{aligned}
$$

For $\left[0^{\circ} / 135^{\circ}\right]$ oriented specimen:

$$
\begin{aligned}
& y_{\text {deg }}=-2.307 x^{2}+20.87 x+298.8 \\
& y_{\text {decom }}=-0.7170 x^{2}+7.963 x+528.3
\end{aligned}
$$

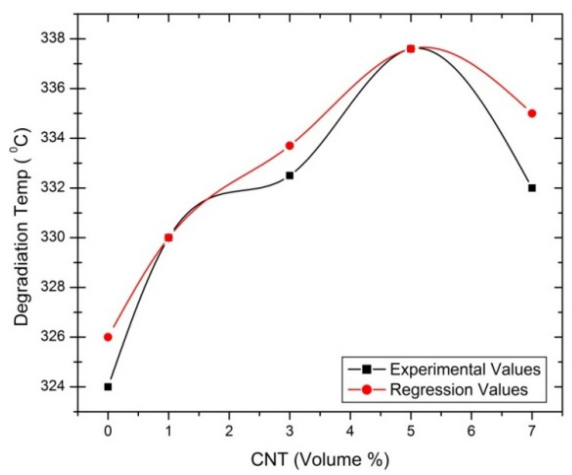

Fig. 23. Regression with experimental values for thermal degradation temperature of $\left[0^{\circ} / 90^{\circ}\right]$ oriented specimen

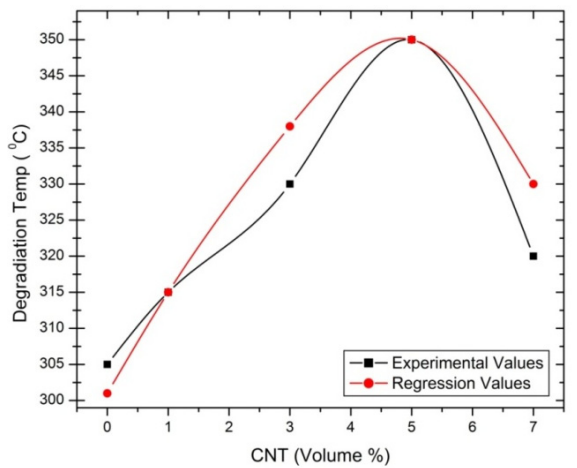

Fig. 25. Regression with experimental values for thermal degradation temperature of $\left[0^{\circ} / 135^{\circ}\right]$ oriented specimen

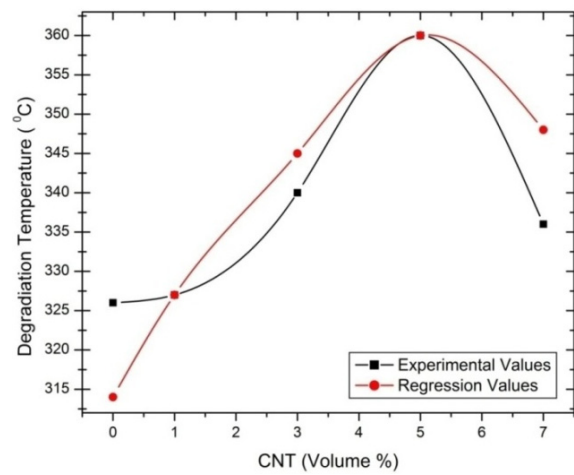

Fig. 24. Regression with experimental values for thermal degradation temperature of $\left[0^{\circ} / 45^{\circ}\right]$ oriented specimen

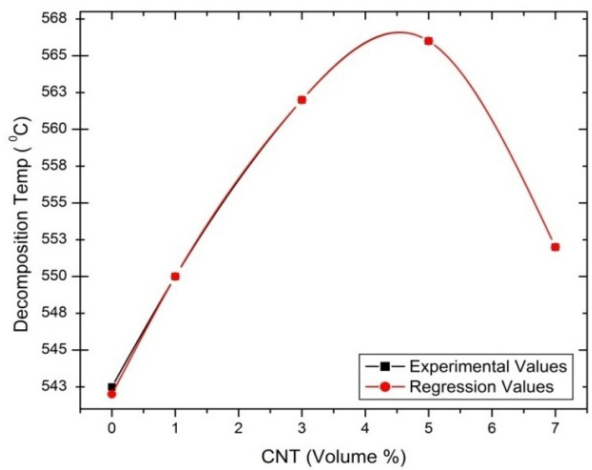

Fig. 26. Regression with experimental values for thermal decomposition temperature of $\left[0^{\circ} / 90^{\circ}\right]$ oriented specimen 


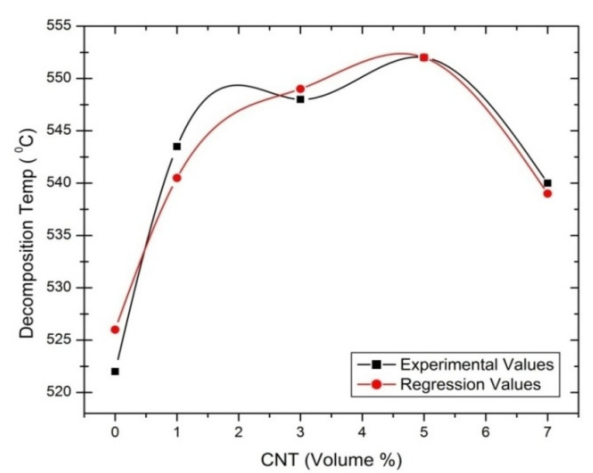

Fig. 27. Regression with experimental values for thermal decomposition temperature of $\left[0^{\circ} / 45^{\circ}\right]$ oriented specimen

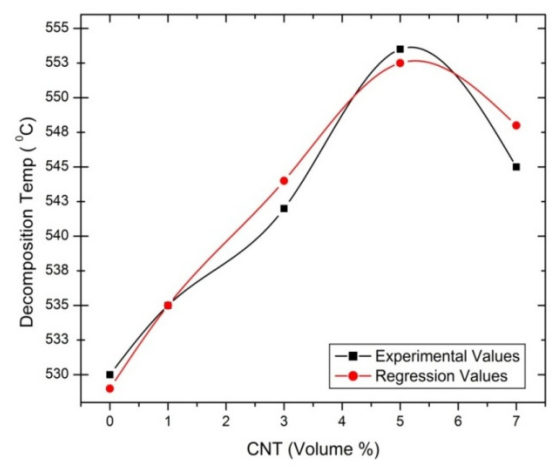

Fig. 28. Regression with experimental values for thermal decomposition temperature of $\left[0^{\circ} / 135^{\circ}\right]$ oriented specimen

The square residual values $\left(R^{2}\right)$ of tensile and flexural strength for proposed percentage of multi walled carbon nanotubes were found to vary between 0.97 to 0.98 respectively in the regression model. As $R^{2}$ of 1.0 represent that the regression curve perfectly fits the data. $R^{2}$ is a statistic that give information about the fit of curve for collected experimental data. In regression, the $R^{2}$ coefficient of determination is the measure of how well the regression line approximates the real data points. The Figs. 23 to 28 shows the comparison between the experimental and predicted strength values.

\section{Conclusions}

The thermal properties of carbon nanotubes based composite are studied. The thermal stability is increasing continuously due to the addition of carbon nanotubes as filler material. The studies are carried out for both, the orientations of the glass mat and also by varying the percentage of carbon nanotubes of composite.

The MWNTs/epoxy composites exhibit higher thermal degradation temperature compared to the neat composite i.e., $324{ }^{\circ} \mathrm{C}, 326{ }^{\circ} \mathrm{C}$ and $305{ }^{\circ} \mathrm{C}$ for their orientations at $5 \% \mathrm{CNT}$. Similarly, the optimum values of thermal decomposition temperature are attained as $566{ }^{\circ} \mathrm{C}, 552{ }^{\circ} \mathrm{C}$ and $554.5^{\circ} \mathrm{C}$ at $5 \% \mathrm{CNT}$ content. The weight loss is also less at $5 \% \mathrm{CNT}$ percentage for different orientation of fibers.

A relationship between experimental and predicted (regression model) values are determined to be strong by the high $R^{2}$ values which were obtained. This means that a good relationship can be expected. The comparison between experimental and predicted values showed that they were in good agreement.

\section{References}

[1] Iijima S. Helical microtubules of graphitic carbon. Nature, Vol. 354, 1991, p. 56-58.

[2] So Hyang Hwa, Cho Jae Whan, Sahoo Nanda Gopla Effect of carbon nano tubes on mechanical and electrical properties of polyimide/carbon nano tubes nano composite. Science, Vol. 43, 2007, p. 3750-3754.

[3] Zhu Bao-Ku, Xu Shu-Hui, Xu Zhi-kang, Xu You-Yi Preparation and properties of the polyimide multi-walled carbon nano tubes (MWNTs) nano composites. Science, Vol. 66, 2006, p. 548-554.

[4] Endo Morinobe, Strano Michael S., Ajayan Pulickel M. Potential applications of carbon nanotubes. Topics in Applied Physics, Vol. 111, 2008, p. 13-62.

[5] Bachtold A., Hadley P., Nakanish T., Dekker C. Logic circuts with carbon nanotubes transistors. Science, Vol. 294, 2001, p. 1317-1320.

[6] Ago H., Petritsch K., Shaffer M. S. P., Windle A. H., Friend R. H. Composite of carbon nanotubes and conjugated polymers for photo voltaic devices. Advanced Materials, Vol. 11, 1999, p. 1281-1285. 
[7] Kasumov A., Deblock R., Kociak M., Reulet B., Bouchiat H., Klodos J. Super current through single walled carbon nanotubes. Science, Vol. 284, 1999, p. 1508-1511.

[8] Baughman R. H., Cui C., Zakhidou A. A., Iqbal Z., Barisci J. N., Spinks G. M. Carbon nano tubes actuators. Science, Vol. 284, 1999, p. 1340-1344.

[9] Xie X. L., Mai Y. W., Ping X. Dispersion and alignment of carbon nanotubes in polymer matrix: a review. Materials Science and Engineering: Reports, Vol. 49, 2005, p. 89-112.

[10] Andrews R., Weisen Berger Mc Carbon nanotube polymer composites. Current Opinion in Solid State and Materials Science, Vol. 8, 2004, p. 31-37.

[11] Xie Xiao Lin, Mai Yiu Wang, Zhou Xing Ping Dispersion and alignment of carbon nanotubes in polymer matrix: a review. Science, Vol. 49, 2005, p. 89-112.

[12] Coleman Jonathan N., Khan Umar, Blau Werner J., Yurii Gun'ko K. Small but strong: a review of the mechanical properties of carbon nanotubes-polymer composite. Science, Vol. 44, 2006, p. 1624-1652.

[13] Ruan S. L., Gao P., Yang Xu, Yu Tx Toughening high performance ultra high molecular weight polyethylene using multi walled carbon nano tubes. Polymer, Vol. 44, 2003, p. 5643-5654.

[14] Ma Peng Chang, Siddiqui Naneed A., Marom Gad, Kim Jang Kyo Dispersion and functionalization of carbon nanotubes for polymer-based nano composites: a review. Composites Part A: Applied Science and Manufacturing, Vol. 41, 2010, p. 1345-1367.

[15] Moniruzzaman M., Winey K. Polymer nano composites containing carbon nanotubes. Macromolecules, Vol. 39, 2006, p. 5194-5205.

[16] Grossiod N., Loos J., Regev O., Koning C. E. Tool box for dispersing carbon nanotubes into polymers to get conductive nanocomposites. Chemistry of Masterials, Vol. 18, 2006, p. 1089-1099.

[17] Du J. H., Bai J., Chang H. M. The present status and key problems of carbon nano tube based polymer composites. Express Polymer Letters, Vol. 1, 2007, p. 253-273.

[18] Zhang Q. H., Chen D. J. Percolation threshold and morphology of composites of conducting carbon black/polypropylene/EVA. Journal of Materials Science, Vol. 39, 2004, p. 1751-1757.

[19] Hill D. E., Lin Y., Rao A. M., Allard L. F., Sun Y. P. Functionalization of carbon nanotubes with polystyrene. Macromolecule, Vol. 35, 2002, p. 9466-9471.

[20] Kim J. Y., Kim S. H. Influence of multi wall carbon nano tubes on physical properties of poly (ethylene 2,6-naphthalate) nano composites. Journal of Polymer Science Part B, Vol. 44, 2006, p. 1062-1071.

[21] Mamedov A. A., Kotov N. A., Proto M. Molecular design of strong single-wall carbon nano tube/poly electrolyte multi layer composite. Nature Materials, Vol. 1, 2002, p. 190-194.

[22] Bakir Ban, Hashem Hai Them Effect of fiber orientation for fiber glass reinforced composite material on mechanical properties. International Journal of Mining, Metallurgy and Mechanical Engineering, Vol. 1, Issue 5, 2013, p. 341-345.

[23] Garcia Enrique J., Wardle Brian L., Hart John A., Yamamoto Namiko Fabrication and multifunctional properties of hybrid laminate with aligned carbon nanotubes grown in situ. Composites Science and Technology, Vol. 68, 2008, p. 2034-2041.

[24] Singh B. P., Prasanta, Veena Choudhary, Parveen Saini, Shailajapande, Singh V. N., Mathur R. B. Enhanced microwave shielding and mechanical properties of high loading MWCNT-epoxy composites. Journal of Nanoparticle Research, Vol. 15, 2013, p. 1554.

[25] Tai Jin Hua, Liu Guo Qin, Caiyi Huang, Shangguan Lin Jian Mechanical properties and thermal behaviour of LLDPE/MWNTs nanocomposites. Materials Research, 2015, p. 1050-1056.

[26] Hsu S. H., Wu M. C., Chen S., Chuang C. M., Lin S. H., Su W. F. Synthesis, morphology and physical properties of multi-walled carbon nanotube/biphenyl liquid crystalline epoxy composites. Carbon, Vol. 50, 2012, p. 896-905.

[27] Bhattacharya P., Sahoo S., Das C. K. Microwave absorption behavior of MWCNT based nanocomposites in X-band region. Compsitesa, 2012, p. 212-223.

[28] Zhan G.-D., Kuntz J. D., Wan J., Mukherjee A. K. Thermal properties of carbon nanotube-copper composites for thermal management applications. Nature Mater, Vol. 2, Issue 38, 2003, p. 793-797.

[29] Cha I., Kyung Kim T., Kyong Lee H., Chan Mo B. Strength and toughening of carbon nanotube reinforced alumina nanocomposite fabricated by molecular level mixing process. Scripta Materialia, Vol. 53, 2005, p. 793-797.

[30] Satish G., Prasad V. V. S., Ramji K. Impact of carbon nanotubes on polymer nano composites. International Journal of Advanced Research in Basic Engineering Sciences and Technology, Vol. 3, Issue 6, 2017, p. 46-60. 